\title{
Accessories course teaching reform under the network media environment
}

\author{
Yanping Xie ${ }^{1, a}$ \\ ${ }^{1}$ Jiangxi Institute of Fashion Technology, Jiangxi, Nanchang, 330201 \\ ${ }^{\mathrm{a} e m a i l}$
}

Keywords: Network media, clothing accessories, the teaching reform

\begin{abstract}
With the rapid growth of social economy, the development of information technology has brought a great revolution to the modern accessories course education in colleges and universities. The low value-added products need more design strength to promote and develop. Institutions at all levels should objectively and reasonably make use of modern information technology. Multimedia and network technology should be used to realize the sharing of resources. Combining with the specific characteristic of accessories course, each institution should make effort to explore the reasonable way to adopt modern information technology in teaching and improve the overall teaching level.
\end{abstract}

\section{Industry development status analysis}

China is a world famous manufacturing country; both the garment industry and accessories industry are the same. A lot of well-known international brands such as Adidas, Nike have set production and processing factories in China. "Made in China" is a famous brand. But only rely on the production capacity, the garment and accessories industry will never lead others in the forefront of development. It will only follow other developed countries' pace. Faced with such situation, the outbreak of accessories design capacity is the trend. The improvement of the design level is a key to break through bottleneck of low value-added accessories products. The progress of technology and development of society put forward new requirements for training highly qualified personnel. The reform of higher education is constantly deepening; accessories courses are facing new challenges and problems.

The development of accessories industry is quite late in our country. The so-called accessories are decoration and practical objects which are related to garments, such as shoes, hats, backpacks and so on. The slow development of domestic industry leads to the neglect of domestic institutions on such major. According to the survey, there are only a few institutions which set up accessories major like Beijing Institute of Fashion Technology, Zhejiang Sci-Tech University, Guangdong Baiyun University and Jiangxi Institute of Fashion Technology. Most of the other schools are vocational training institutions or give priority to vocational education. With different background of each institution, the focus of curriculum system is different. In this environment, the development of accessories courses will face many problems. First, in many institutions the teaching methods are still the traditional workshop style that masters train an apprentice. A style is used term by term, the era information updates slowly. This kind of teaching method can only bring out a batch of cobbler or package carpenter. The design capability is very low which has a large gap between the international design levels. Second, students can design but can't manufacture. Institutions only pay attention to students' performance ability and ignore the practical operating ability. In the process of making pattern, teachers often use hand-drawing. It is not intuitive and needs a lot of experience and feeling which make students feel difficult to learn then lose interest in learning. It is proved by facts that the application of highly developing modern information technology in accessories courses can have the effect of getting twice the result with half the effort. Because present form of the traditional teaching is difficult to demonstrate the contents of accessories courses comprehensively and intuitively, especially the complex and difficult to operate part. It is difficult for students to learn, let alone the 
easy and pleasant study process which will lead to students' lack of motivation to learn and even weariness and ultimately can't achieve good teaching results. With the popularity of modern information technology, all kinds of accessories software come into being. A variety of professional accessories network platform are built and widely used among various subjects such as the design course and the pattern making course. The appearance of professional courses software helps teachers to display the teaching process preferably and more intuitively which improves teachers' educational concept and thinking method. The quality of teaching and learning environment of professional curriculum can be improved at the same time. The course content is in good combination with the market. Students' design level can get good confirmed on the network platform. Therefore, it is imperative to combine accessories courses with modern information technology. All relevant professional colleges should promptly apply information technology to the teaching process of professional curriculum and constantly update in real time. Only in this way, can we cultivate comprehensive entrepreneurial talents who are suitable for the market demand.

\section{The application of modern information technology}

Making and teaching of multimedia courseware. The MAI (Multimedia Assisted Instruction) means carrying out teaching activities with multimedia methods such as CD-ROMs, videotapes and slides. Multimedia courseware teaching methods are updated from the traditional teaching methods which makes a breakthrough of the traditional chalk and blackboard mode. In the past accessories design courses, the drawing of design sketch can be only achieved by pasting a piece of paper on the blackboard while teachers stand on a stool to demonstrate the painting process. Students sit in the back row often can't see clearly which requires teachers to repeat over and over again in private. While in making multimedia courseware, the process of drawing can be recorded as a video to demonstrate closely. It is easy and clear for students to watch. Teachers can also save energy to focus more on presentation and management of classroom order which puts an end to the lazy and deserted behavior of students in the back row. The traditional classroom teaching mode often takes the manuscript of students in the past as demonstration. The manuscript is easy to be damaged and very inconvenient to carry. While the excellent work presented in the multimedia courseware is not confined to the production of teachers and students, ancient or modern, popular or eliminated works can be very intuitively displayed. The traditional demonstration method can only be circulation, while the presentation of multimedia projection is more clear and shocking. The large capacity of multimedia courseware makes it have great practicability. The multimedia courseware such as PPT or FLASH can make it more enjoyable and easier for students to accept the new content through audio, video and animation. Especially for accessories design courses, the fashion trend updates quickly. Using multimedia courseware can collect and summary data by powerful network information resources. What they get can be displayed and communicated in real time in the classroom. Different from the constant interpretation of a variety of styles and trends by traditional teachers, this method has a clear advantage with greater amount of information. In the past, due to too much influence by traditional Chinese education culture, teachers are always playing the role of disseminators of knowledge. Teachers are in control of the classroom, while students are learning passively. The design of multimedia teaching software follows the students' cognitive law and organizes teaching information in a nonlinear and hypermedia way. Students can proactively and individually learn according to their own characteristics and circumstances to change the traditional passive learning habits. Multimedia technology provides us an opportunity for teaching reform and meets the teaching needs. It has a perspective effect which traditional education mode can't provide.

The application of professional course software. The accessories course software can be classified into two parts: structure and design. The most commonly used and popular software is Photoshop, Coreldraw and AI. With the development of accessories industry, the classification of software is increasingly refining, for example, the pattern making CAD software, the shoes design max software and the jewelry design CAD software. Such software greatly improves the traditional inefficient mode by hand-drawing and hand-pattern-making. Photoshop can not only modify the 
design sketch, but also draw sketch more efficiently. Hand-drawing sketch is not only time-consuming but also requires a higher art form capacity for designers. Students with good idea but low expression ability are often overwhelmed, which makes them lose courage and interest for design. Such software can help students regain confidence and show their ideas with endless network material. Therefore, the application of professional software can improve students' practical ability and stimulate and reinforce their motivation. The appearance of professional software improves the professional skill of teachers and reduces their workload. For example, in the presentation of making pattern, repetition rate is high and the content display is not complete. The CAD software makes students able to see the whole steps in front of computers intuitively and comprehensively. The practice is also simpler and less wasteful. In the process of correcting homework, teachers can better point out the mistake and make changes. The appearance of professional software narrows the distance between enterprises and schools. In the personnel docking process between schools and enterprises, it preferably meets the modern enterprises' requirement for talents.

The independent network study.

Cultivation of independent study ability. Although the teaching contents and courseware in classroom are diverse and interesting, they inevitably possess teacher's subjective consciousness. The awareness of students may be affected and tied up. In information age, teachers are no longer the only center and absolute authority in classroom. Independent study will be the new development trend of education which injects renascent vitality into traditional education mode. Multimedia and network information technology provide students possibility to acquire knowledge. Therefore, the basic method that teachers talk and students listen is bound to be replaced by students' interactive information retrieval ways. In the relationship between teaching and learning, students are the core and real theme, while network is undoubtedly the best tool for the independent study.

Cultivation of innovation consciousness. The French biologist Bernard once said that "creativity can't be taught, the so-called creativity teaching refers that students are encouraged to express their ideas, only in this way their creative talents can be played". It can be seen that teachers can only act as advisers rather than leaders. Creativity can't be taught, students' subjective initiative is the focus. In the teaching and practice activities, the cultivation of discovery and creation consciousness should be emphasized and paid attention to. The use of multimedia and network platform can broaden students' horizon and provide a powerful environment for cultivating innovative consciousness. Of course, the innovation education is not just simply measured and determined by the amount of information. The most important thing in information age is not the amount of information but the ability to access, analyze and use information. It contains the ability for learners to efficiently obtain information, to proficiently and critically evaluate information, to effectively absorb, store and retrieve information. The building of network platform can make a good evaluation of these abilities for students. Using multimedia forms to express information, creating information utilization ability, turning information into autonomous and effective learning and communication ability are the main and ultimate goal of personnel training in contemporary universities.

\section{Conclusions}

The rapid development of network information technology has changed the traditional teaching mode, updated teaching methods and means which makes the modern university education develop towards a more modern and personalized direction. Institutions at all levels should objectively and rationally use modern information technology, make full use of multimedia and network technology to realize the sharing of resources. They should combine the special features of accessories major and make efforts to explore reasonable ways to apply modern information technology in accessories course. In this way, can we improve the overall level of professional education and train more comprehensive and professional talents to supply outstanding design talents for China's accessories industry and contribute to the development of the industry. 


\section{References}

[1] L. L. Han, Investigation on the influence of network and Countermeasures, Higher Education Forum, 4(2004) 25-29.

[2] L. S. Yi, Influence of network on college students and Countermeasures, Petroleum Education, $3(2003) 87-88$.

[3] Mao L.D: Network Information Science, Vo1. 4 (2003) No.6, p. 143-150.

[4] Kedong Li, The core of Digital Learning -- the integration of information technology and Curriculum, E-education Research, 8 (2001) 46-49. 